\title{
Linguistic Means of Evaluation of Quantity in Texts Containing Numerical Lexemes
}

\author{
Natalia Kim, and Andrey Narushevich* \\ Dept. of the Russian Language and Literature, Taganrog Institute named after Anton Chekhov (Rostov State University of \\ Economics), Taganrog, Russia
}

\begin{abstract}
This article is devoted to the analysis of linguistic means of explicating evaluation in utterances containing numerals. The evaluation of certain amounts and numbers can be encountered at all levels of linguistic expression. It is shown that both quantitative and axiological evaluation of a certain number or amount, expressed by a numeral, can be verbalized at the surface level of the semantic structure of the utterance with either stylistically colored or neutral lexemes that belong to different parts of speech. Stylistically colored lexemes often combine evaluation semes (such as "a lot" and "bad"). The evaluation of a certain number expressed by a numeral with the primary meaning can be detected as a hidden presupposition and / or communicative meaning of a statement including a numerical lexeme. Pragmatic factors that determine the evaluation are considered. It is noted that in speech, explicit and implicit ways of expressing evaluation can be combined, which leads to an "amplification" of the evaluation and is manifested in the simultaneous use of linguistic units of different levels.
\end{abstract}

Modern research in linguistics is characterized by unflagging interest to the study of semantics, and the functioning of numeric lexemes in speech, in particular, of numerals. The cognitive aspect of numerals [1], the compatibility of Russian nouns with paucal numerals 2-4 [2], cardinal numbers in the Russian language [3], the functioning of numerals in fiction [4] have all received considerable attention.

Linguistic means of expressing evaluation - the most important process and the result of human cognitive activity - have been extensively studied [5]. In addition, the facts of "transition of some numerals from determinate to indeterminate ones" have been pointed out; numerals have also been described as elements of the indeterminate evaluation set [6]. However, the evaluation of a number expressed by a numeral, with the help of linguistic units of different levels, has not been analyzed so far.

In the text, a certain numeral can receive both explicit and implicit evaluation characteristic. The utterance Well, is fifty rubles really big money? (I. Goncharov) contains a hidden evaluation of the pronounced amount as insignificant: the rhetorical question is a typical discursive metonymy, accompanied by a change of modality - fifty rubles is not really big money is. The quantitative evaluation in the following statement is expressed by an adjective indicating an insignificant amount: They say he returned from the campaign, and brought back a hundred rubles. A hundred rubles is little money is, but you could live on it somehow (M. Saltykov-Shchedrin). Thus, two types of evaluation can be found in utterances with numerals: explicit (verbalized, direct) and hidden presuppositional and / or communicative; the perception of the latter is based on various presuppositions, "as the speakers are those who have in mind things with words, and not the language itself" [7].

Explicit at the surface level of the semantic structure of the text, the evaluation of a certain number expressed by a numeral can be quantitative (many / few) or axiological ( good/bad):

1) - Mother writes that she'd given you a thousand rubles: that's not enough, said Pyotr Ivanych (I. Goncharov);

2) - At the beginning, I served a whole year without pay, and you suddenly got a good salary; it's seven hundred and fifty rubles, and with a bonus, it's a thousand. Perfect for the time being! (I. Goncharov).

The semantic structure of utterances with a hidden evaluation presupposition at the deep level includes the knowledge of the evaluated stereotype, as well as scales of assessment, and norms that the participants in communication are aware of.

1) Passion and fear are strong feelings. Like boiling water. A person cannot live in boiling water. A person must exist with a temperature of thirty-six point six (V. Tokareva);

2) Tarnovsky's a daredevil; on first name terms with whales, and crocodiles, and demons; pulse 225, temperature $42.8^{\circ}$ (A. Chekhov).

Communicants' ideas about the normal temperature of a person's body are revealed as an implicit component

*Corresponding author: anarushevich@yandex.ru 
in the semantic structure of the statements cited above. So the temperature $36.6^{\circ} \mathrm{C}$ is evaluated by the listener as an appropriate standard, $42.8^{\circ} \mathrm{C}$ is seen as exceeding it.

Statements with hidden evaluations with presuppositional and communicative meaning include three "layers" of semantics: When will postmen get a pay rise? We get 3600. How can one live on it? (From a newspaper article).

At the surface level of the semantic structure, the highlighted utterance contains an explicit communicative meaning We get 3600 , stipulated by the lexical and grammatical filling of the syntactic pattern that includes the definite-quantitative meaning of the numeral " 3600 ".

The hidden presuppositional meaning of this statement "not enough" is founded in the communicants' perceptions of the living standard, the average salary, and so on. Such knowledge is included in the semantic structure of the evaluation as a nonverbalized component.

The implicit communicative evaluation meaning of "not enough" as hidden content of the message is revealed through the establishment of implicative relations between the explicit meaning (We get 3600) and the implicit presuppositional meaning (3600 is not enough). The modal frame of the statement is "We get 3600 , and the speaker thinks it's not enough." It is the implication of this meaning that allows keeping the logic of the text. The semantics of the question "How can one live on it?" found in post-text is in accord with the corresponding evaluation meaning.

Evaluation can be explicated on the surface level of the semantic structure of the utterance in the case of using numerals in the secondary indefinite (cardinal and ordinal) meanings.

The numerals one hundred, one thousand, one million, one billion have recorded in dictionaries secondary indefinite quantitative meanings "an indefinitely large number; many, very many" [6, 850], "extremely large number, an indefinite number of people or things" [6, 349]

1) -... I will remind you that here, in this very place, you have sworn a hundred times to be mine (I. Goncharov);

2) - I told him a thousand times: take off your coat. He wouldn't (V. Tokareva);

3) - Listen at least once in your life carefully, I came for business, I want to calm down, solve a million painful questions that worry me (I. Goncharov).

Other cardinal numerals express evaluation as purely verbal numerals that develop in the process of semantic analogy and are similar to the evaluated actual meanings.

The estimation of quantity is the result of the mental process of generalization, when the consciousness grasps the general impression of a quantity. In this case, the exact amount may not be known to the speaker:

1) - But I do know it [the script]. I've read it forty times (V. Tokareva);

2) ...I thought: Why the hell would she go to that exhibition in this weather, get squeezed in the subway, among wet coats? Does she need it? But it was inconvenient to cancel. Seventeen times I called, pestered, and to cancel now?... (V. Tokareva).
The number that is definite in objective reality and is known to the speaker (two "whys" in the following example) can also be interpreted as a significant one:

Why go to Italy to see where she lives? Why is it clear to everyone, but not to her? Forty thousand "whys" (V. Tokareva).

Both cardinal and ordinal numerals reflect the objective properties of a discrete quantity, therefore, in the structure of a definite quantitative meaning, a discrete seme is found (in the phrase twenty-three years, for example). The numeral used to indicate the degree of manifestation of something can lose this component of the semantic structure (twenty-three times smarter):

- What a clever girl she is! How old is she? Eighteen. - And you are twenty-three. Well, my dear, she is twenty-three times smarter than you (I. Goncharov).

The ordinal numerals hundredth and thousandth can also express evaluations recorded in dictionaries as secondary adjectival meanings: hundredth - "multiple, countless" [6, 778] and thousandth - "innumerable, manifold" $[6,850]$. In the case of the use of these lexemes in the text, the evaluation is explicated on the surface level of the semantic structure of the utterance due to the actualization of these meanings:

- Such dreamers like you. Always on the alert, catching a breeze of true friendship and love... For the hundredth time I'll say: I've come in vain (I. Goncharov).

Other ordinal numerals can have indefinite ordinal meanings in specific communication situations:

Zverev ate little and did not understand why there were so many plates. But when they sat down, when the smell hit his nose, he realized how wonderful it was to have so many different foods: hors-d'oeuvres, first course, second, twenty-second ( $\mathrm{V}$. Tokareva).

The lexeme of the compound numeral twenty-second is used to express the meaning "occupying the last place in the set consisting of a significant number of units". In this case, the idea of a significant number is supported by the elements of the context: the adverbial lexeme many and the adjectival lexeme different, as well as the quantitative semantics of the coordinate array. Not fixed in the language system, such meanings are nevertheless manifestations of linguistic regularity: paradigmatically combined (at the level of their basic meanings) words, including numerals, tend to form similar secondary meanings.

Evaluation of quantity expressed by a numeral can be expressed at the surface level of the semantic structure of the utterance by different parts of speech. This can be a rational and emotionally expressive evaluation "a lot / little", "good / bad".

Rational evaluation is assigned to the amount expressed by the numeral using stylistically neutral lexemes - general and specific words belonging to the different parts of speech. It can be specific adverbial lexemes containing semes low and high in the semantic structure of meanings characterizing, for example, the air temperature:

1) - I think he forgot to take his warm underwear. He'll catch a cold ... my husband. It's cold there. Fifty degrees below zero. (V. Tokareva); 
2) - "My, but it's hot!" exclaimed Yegor, unbuttoning his waistcoat. "The temperature must be seventy! (A. Chekhov)

Emotionally expressive evaluation is expressed by stylistically colored words of various parts of speech, which are characterized by belonging to the colloquial style, and has the appropriate stylistic coloring.

Let us consider the following two utterances:

1) Released to freedom in Kryukovo, to go to his native penates he had to ... leg twenty miles (A. Chekhov);

2) He was in half-conscious, all beaten, cut, his face bluish and all swollen. It turned out that during the previous night he had walked to the Dubrovinsky manor, which was twenty miles away from Golovlev (M. Saltykov-Shchedrin).

In the first example, the evaluation of a certain number (the twenty-mile-distance) is explicated by a stylistically colored verb. The lexeme leg means "go or walk etc. a large distance at a time" and is marked as colloquial. [8, 476]. In the second statement, the lexeme walked is stylistically neutral and does not contain a number evaluating seme. In this utterance, a hidden presuppositional evaluation meaning is present. The semantically loaded component "twenty miles away" refers the reader to his or her notion of twenty miles as a significant distance covered on foot.

The seme of significance of the indicated number is found in the semantics of the substantive lexeme of juggernaut, which refers in the colloquial style of speech to "something that is large, heavy, or cumbersome" [8, 338].

- It's no joke - four thousand souls! To manage such a juggernaut in my age! (M. Saltykov-Shchedrin).

It should be noted that in speech, there can be a combination of explicit and implicit ways of expressing evaluation, which leads to an "amplification" of the meaning. This is manifested in the simultaneous use of linguistic units of different levels (specifically, lexical and syntactic). To express the evaluation, for example, the semantics of an exclamatory sentence can be used. Knowledge of the meanings of syntactic units is the implicit component of the speech act, being the knowledge of communicants about the language, while knowledge of the meanings of language units is the knowledge of the language itself.

Quantitative evaluation has axiological potential, which makes it possible to obtain value characteristics, for example, $b a d$, in the situation described in the utterance with the numeral.

1) Shubin showed up. He was forty minutes late, which was swinishness (V. Tokareva).

The dictionary meaning of the word swinishness is marked as disapproving. In addition, the negative evaluation seme is found in the interpretation of the meaning as "an ill-mannered action" [8, 725].

2) The weather is really lousy: it's cold and it's been raining for 4 days in a row. I got less money than I thought I would (A. Chekhov).

The seme of axiological evaluation is recognized in the interpretation of the value of general adjectival lexemes bad, badly. Lousy - "colloquial, about what is inferior, bad" [8, 177].

3) - "Nothing special!", said the best man. "So-so ... even ugly, you can say. And the face is kind of stupid ... Adam's apple's two meters on his neck" (A. Chekhov).

A negative evaluation of the excess of the quantitative norm (Adam's apple's two meters) is explicated by lexemes ugly, and stupid.

Stylistically colored lexemes often combine evaluation semes in their meanings, for example, "many" and "bad":

-He goes to taverns, he does not keep horses, he's first time in the house, and guzzled up a whole decanter of rum and five glasses of vodka (M. SaltykovShchedrin).

The dictionary definition of guzzle is marked as coarse, and it also includes a lexeme big that explicates a significant amount. It should be noted that in the semantic structure of the utterance above, the statement reveals both explicit and implicit evaluation. At the surface level of the semantic structure, the evaluation is explicated, as has been shown, by the lexeme guzzled. Being constructed as a complex sentence with the semantics of nonconformity, this statement as a whole has pronounced evaluation semantics, and contains an evaluated communicative meaning - condemnation. It is associated with the description of the speaker's notions that are inconsistent with normative concepts of the person's permissible behavior in the given situation (guzzled up a whole decanter of rum and five glasses of vodka) in the second predicative part, who is first time in the house, in the first predicative part.

A quantity expressed by a word combination with a numeral can get a positive evaluation in speech:

- Don't lose you kerchiefs, darling: exquisite lawn! Bought it at Mikheev's for two and a quarter. All white goods (I. Goncharov).

Quantitative and value judgments often accompany each other. The evaluation exquisite makes one think of the price of two and a quarter as significant: expensive goods are characterized, as a rule, by high quality.

The expressive evaluation of the number as "little and bad", or "many and good" can be explicated by metaphorical lexemes of adjectives that retain in their secondary meanings the evaluation mark of the primary nomination:

1) Finally, buyers come, but the prices they give are sad-twelve rubles for a quarter of rye, for a quarter of oats - seven rubles in banknotes (M. SaltykovShchedrin);

2) But alas! So little was he accustomed to dealing with money, so absurdly did he understand the size of real life, that the fairy-tale yearly salary of one thousand rubles was only enough for a very short time (M. Saltykov-Shchedrin).

An explicit evaluation of a certain number, expressed by an adjective in a shifted attribute position can be expressive ("maximum thermometer"):

And the doctor brings the maximum thermometer to Nellie's eyes. 
-Temperature's nearly forty. Just can't bear it! I ... I cannot even be sitting. Excuse me, I'll lie down ... (A. Chekhov).

The direct nomination is "maximum temperature on the thermometer".

At the surface level of the semantic structure of the utterance, a rational and emotionally expressive evaluation can be simultaneously presented. The number of years lived, expressed by the quantitative nominal phrase a hundred years, is objectively evaluated as a significant lexeme of the parametric adjective long. Because of the use of the figurative quantitative nominal word combination, an hour and a half, the definite number of one hundred years receives an expressive evaluation of "short": Even if life turns out to be a long one, a hundred years, it is only an hour and a half. Even less, like a film in the cinema (V. Tokareva). The Perception of the evaluation of the duration of life one and a half hours is based on the "unconscious" [9] linguistic knowledge of the communicants - language presuppositions.

The expressiveness of an evaluation can be achieved with the help of a contradictory combination of evaluations "a lot" / "little". The explicit evaluation, contradicting the quantitative normative ideas of communicants, in particular, about the age, is used to create a stylistic effect, which is associated with the functioning of linguistic units in the fiction texts. Such evaluation can be supported by the semantics of syntactic constructions (exclamatory sentences), stylistic coloring of lexemes ("old woman", "dog's old age"), etc.

1) When will I fall in love not forcibly? After all, I'm almost 30! I've never met a better woman than Vera, and never will... oh, dog's old age! Being old at 30! (A. Chekhov);

2) Dimych is not older than Sasha, but he's old anyway, he was an old man even when he was three (V. Tokareva);

3) - With you, I've been an old woman since thirtyfive (V. Tokareva).

The evaluation of the objective situation described in the utterance with a numeral can be given with the help of verbs of denoting the emotional attitude:

The next day we went together to the Morozov hospital. The eye department was on the fifth floor, no elevator. Faina walked, ascending her hundred kilos, and was grumbling discontentedly (V. Tokareva).

The quantitative nominal word combination on the fifth floor, used in this text, refers the listener to the notion that a rise to the fifth floor without an elevator is associated with physical stress. Separation of the word form no elevator reflects the author's intention to emphasize this and actualize the potential seme high. Negative evaluation is explicated by the use of the colloquial verb grumble.

Verbal lexemes expressing an emotional response, explicate the evaluation undifferentiated as significant or minor, positive or negative:

- Well, you do not understand anything. Let's go further. You say that you have no friends, and I always thought you had three of them. - Three? - exclaimed
Alexander, - I used to have one, and even that one ... (I. Goncharov)

The verb of the emotional attitude exclaim gives an evaluation of the number three as exceeding the real one.

The evaluation received by the number expressed by a numeral can be "pragmatically motivated" [9] due to the situation of communication, the personal qualities of communicants, or the goals of communication. In this regard, the same amount can evaluated in different ways:

- How much is a pair of perches? - Just twenty kopecks. - It was always fifteen, but now it's twenty (M. Saltykov-Shchedrin).

The evaluation of the price of twenty kopecks as an insignificant one is made by a lexeme with a diminutive suffix [9] and is conditioned by the speaker's goal to sell perch at a new, higher price. In the statement it was always fifteen, but now it's twenty, there is a negative evaluation by the buyer of the increase in the value of the goods.

The pragmatic factor underlines the evaluation of the quantity expressed by quantitative nominal combination $a$ thousand and five hundred rubles as insignificant by the personality of the speaker, a young man who took discounted a false bill for a considerable sum. The author's irony is based on a combination of inadequate evaluations, subjective one (some - "little") and objective (one thousand five hundred rubles - "a lot"):

He discounted a false bill ... He had not expected his aristocratic relatives to raise the storm because of some thousand five hundred rubles! (A. Chekhov).

There is such pragmatic category which the speaker can determine as the evaluation of age. In the question Old? in the dialogue between the matchmaker and the mother below, the request contains evaluation meaning [11]. The response, the words of the matchmaker, contains an explicit evaluation mature, middle-aged. The quantitative nominal phrase around forty-five serves as an explanation for the evaluation. Based on the idea of forty-five years as an age that is significant in this situation (the age of the groom of the twenty-year-old daughter), the listener (mother) evaluates as "oldish":

- Old? - Not really... a mature man. Must be around forty-five. Middle aged. - Oldish (M. SaltykovShchedrin).

Evaluation of a certain number can be found at all levels of linguistic expression. Numbers expressed by numerals can receive both explicit and implicit evaluation characteristics.

\section{References}

1. J. Gvozdanović, The Encyclopaedia of Language and Linguistics 8, 736 (Elsevier, ed. 2, 2006)

2. M. Xiang, B. Harizanov, M. Polinsky, E. Kravtchenko, Lingua 121, 548 (2011)

3. G. Corbett, Lingua 46, 555-368 (1978)

4. A. Lykov, Numerals in Modern Russian: Semantics, Grammar, Functions (SFEdu, Rostov-on-Don, 2007) 
5. Y. Volf, Functional Semantics of Evaluation (Editorial URSS, Moscow, 2006)

6. L. Chesnokova, The Numeral in Modern Russian. Semantic, Grammar, and Functional Aspects (Gefest, Rostov-on-Don, 1997)

7. J. Colomina-Almiñana, Lingua 206, 112 (2018)

8. The modern explanatory dictionary of the Russian language, S. Kuznetsov, Ed. (Norint, St. Peterburg, 2001)

9. F. Li, X. Lei Zhu, Z. Yang, Z. Dienes, Consc. and Cognit., 22, 174 (2013)

10. A. Capone, Lingua 198, 22-37 (2017)

11. N. Kim, A. Narushevich, Statements and Negations in Expressions with Numerals In: Shcheulin Readings. Proceedings of Intern. Conf. 1, 58 (2016) 